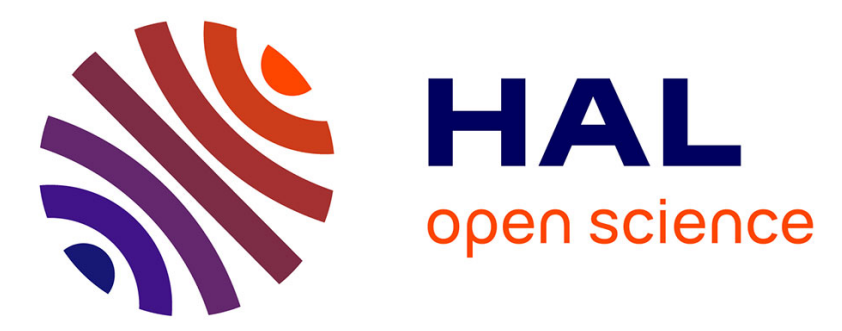

\title{
Flow analysis inside a Pelton turbine bucket
}

Béatrice Zoppé, Christian Pellone, Thierry Maître, Pierre Leroy

\section{To cite this version:}

Béatrice Zoppé, Christian Pellone, Thierry Maître, Pierre Leroy. Flow analysis inside a Pelton turbine bucket. Journal of Turbomachinery, 2006, 128, pp.500-511. 10.1115/1.2184350 . hal-00232705

\section{HAL Id: hal-00232705 https://hal.science/hal-00232705}

Submitted on 24 Jan 2020

HAL is a multi-disciplinary open access archive for the deposit and dissemination of scientific research documents, whether they are published or not. The documents may come from teaching and research institutions in France or abroad, or from public or private research centers.
L'archive ouverte pluridisciplinaire HAL, est destinée au dépôt et à la diffusion de documents scientifiques de niveau recherche, publiés ou non, émanant des établissements d'enseignement et de recherche français ou étrangers, des laboratoires publics ou privés. 


\section{Flow Analysis Inside a Pelton Turbine Bucket ${ }^{1}$}

The aim of this work is to provide a detailed experimental and numerical analysis of the flow in a fixed bucket of a Pelton turbine. The head, jet incidence, and flow rate have been varied to cover a wide range of the turbine functioning points. The experimental analysis provides measurements of pressure and torque as well as flow visualization. The numerical analysis is performed with the FLUENT code using the two-phase flow volume of fluid method. The results present a good consistency with experimental data. In particular, the pressure distribution is very well predicted for the whole range of the studied parameters. A detailed analysis of torque and thrust allows evaluating the losses due to the edge and the cutout of the bucket. These results give insight into the benefit we can expect of steady flow calculations through the optimization process of the design of Pelton turbines.
B. Zoppé

Laboratoire des Ecoulements Géophysiques Industriels, B.P. 53, 38041 Grenoble Cédex 9,

France

C. Pellone

Centre National de la Recherche Scientifique, Grenoble, France

T. Maitre

Institut National Polytechnique Grenoble,

France

P. Leroy

ALSTOM Power Hydro, B.P. 75, 38041

Grenoble, France

\section{Introduction}

Up to now, Pelton turbines have been designed using experimental techniques and semi-empirical methods. The reason is that the flow in the bucket is unsteady, separated from air by an unknown free surface (two-phase flow), and developed within moving boundaries. These features concern mainly the ideal "firstorder" inviscid flow field involved in loss mechanisms, such as bucket back splashing or jet interference. The prediction of this flow represents a great challenge for numerical modeling. A second group of difficulties deals with the actual flow. We mention, for instance, the enlargement or atomization of the jet and water layers, the secondary flow field at the injector outlet, the wake effect behind the injector nozzle, the gravity deviation of the water, etc. These phenomena, depending on Froude, Weber, and Reynolds numbers, are intimately linked to loss mechanisms in the turbine. They also depend on the turbine design. Though they are of second order compared to the first-order aforementioned flow, their understanding is necessary to improve the efficiency predictions, particularly in the case of model to prototype transposition laws.

Nowadays, the performance of computers allows numerical investigations of the flow in both fixed and rotating parts of the Pelton turbine. Concerning the internal viscous flow in the upstream guiding pipes, Reynolds average Navier-Stokes (RANS) approach has proved its relevance. As an example, we note that the calculations precisely predicted the secondary velocity field at the outlet of the injector [1]. Concerning the external flow in the bucket, much work has been performed during the last few years using two kinds of sheet description.

- The first one uses discrete distribution of particles, spherical pellets, or strips to discretize the water sheet. The corresponding methods have been applied for a twodimensional (2D) fixed and rotating flat plate [2] and for three-dimensional (3D) rotating buckets [3-5]. In these methods, no grid is needed and the air flow is not calculated.

- The second corresponds to more classical grid-based computational fluid dynamics (CFD) approaches using a free-surface tracking method (generally, the well-known

\footnotetext{
${ }^{1}$ The bucket geometry is partially provided due to confidentiality.
}

volume of fluid VOF method). Steady buckets were calculated by several authors [6-10]. Rotating buckets were also modeled with different levels of approximations. Some calculations were performed on a fixed grid with a moving jet at the inlet $[6,11]$. In this case, only one bucket is considered and the cutting of the jet inlet by the following bucket is not modeled. Other calculations are performed with a stationary grid zone (stator) containing the jet inlet and a rotating zone (rotor) containing the buckets. The sliding mesh technique allows connecting the two regions. Mack and Moser [12] Mach et al. [13], and Zoppé [14] considered three adjacent buckets. This approach provides the conditions in the middle bucket that are common to all revolving buckets. The only limitation seems to appear at a high number of injectors (46), where jet interference phenomena occurs [15]. By assuming a periodic flow between two successive injectors, Perrig et al. [16] avoids this limitation. It is noted that only Mack compared calculated pressure with experimental time-dependent pressure signals.

It is noted that much work has been done in the field of bucket flow modeling, but very few of them are compared to experimental measurements. For example, only Kvicinsky [11] compared the calculated pressure distribution to experimental data. For this reason, the object of this work is to perform RANS modeling of a steady bucket compared to global and local measurements for a significant range of functioning parameters. Vizualizations were also planned to support a better understanding of the flow. A second object of the work is to use numerical modeling to quantify the different causes of thrust loss in the bucket separately. The results, presented at the end of this paper, are used to provide insight into the benefit we can expect of steady-state flow calculations through the global process of Pelton design optimization.

\section{Experimental Study}

The experimental study was conducted in the laboratories of Alstom Power Hydro (Grenoble, France). The bucket, characteristic of a Pelton turbine, is placed in the uniform flow created by a cylindrical jet. This study mainly provides a cartography of pressures inside the bucket and total forces values on the bucket. The bucket is placed at various incidence angles; several jet diameters and head heights are used.

2.1 Test Implementation. The testing rig is schematized in Fig. 1. A centrifugal pump, driven by a variable speed $250 \mathrm{KW}$ 


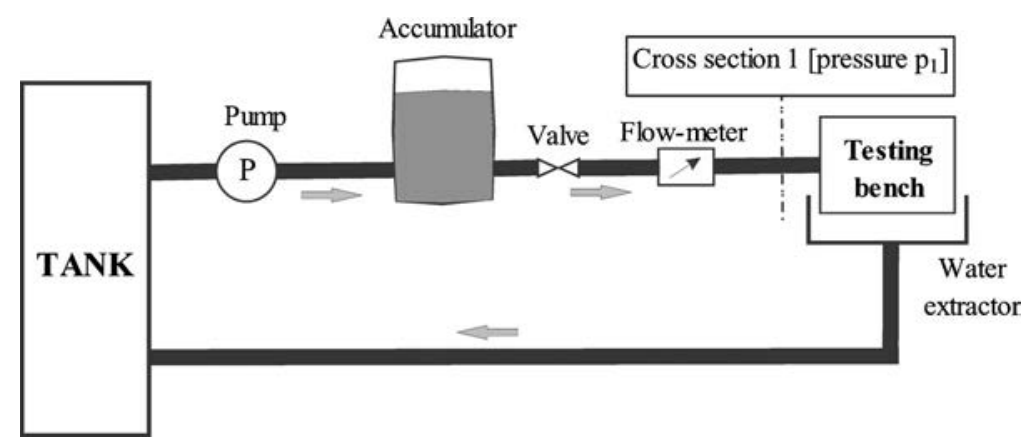

Fig. 1 Diagram of the testing rig

powered motor, supplies the test bench by means of a $200 \mathrm{~mm}$ dia pipe. For a given series of tests, the speed of rotation of the pump is maintained constant. The flow rate inside the pipe is measured by means of two flowmeters: an electromagnetic flowmeter (Krohne) and a magnehelic gage (Brooks). The measurement of the first allows the verification of the second. In order to adjust the jet diameter, an orifice is placed at the pipe outlet.

The static head, corresponding to the pressure difference between the interior of the pipe and the atmosphere is measured by means of two differential pressure sensors Rosemount DP27 and E22 located just upstream from the testing bench. The pressure and velocity upstream of the orifice are designated by $p_{1}$ and $U_{1}$ (cross section 1 on Fig. 1). The atmospheric pressure and the jet outlet velocity are designated by $p_{\text {atm }}$ and $U$. The net head $H_{n}$ $=U^{2} / 2 g\left(g=9.81 \mathrm{~m} / \mathrm{s}^{2}\right.$ is the gravitational acceleration $)$, the static head $H_{s}=\left(p_{1}-p_{\text {atm }}\right) / \rho g\left(\rho=998 \mathrm{~kg} / \mathrm{m}^{3}\right.$ is the water density $)$ and the dynamical head $H_{d}=U_{1}^{2} / 2 g$ are simply connected by the Bernoulli relation $H_{n}=H_{s}+H_{d}$.

The measurement of the flow rate $Q$ gives the velocity $U_{1}$ (so $\left.H_{d}\right)$, the measurement of $p_{1}$ gives the static head $H_{s}$, which leads to the $H_{n}$ value and thus provides an experimental measurement of the jet velocity $U$. The adjustment of $H_{n}$ is ensured using the two valves.

A photograph of the test bench is presented in Fig. 2. It consists of the steel frame, the water jet intake, the water sheet extractors, the water jet extractor (for safety), and the instrumented bucket. In order to limit the flow disturbances related to the singularities of the testing rig (elbows, valves, etc), the bench is placed at the end of a rectilinear pipe, $3.5 \mathrm{~m}$ long.

The water sheet extractors are curved pipes of a rectangular cross section. They make it possible to direct the water sheets flowing out the bucket toward the collecting container located under the test area. The extractors position is adjusted according to the bucket incidence. The quantity of water that these elements must direct is significant; in fact, protection was added in order to reduce the splashes near the measurement zone and the backflows on the jet.

The orifice $\phi_{d}$ diameter, narrows the water jet to a minimum value of $D$. One designates by $S=\pi D^{2} / 4$ the cross section of the jet upstream of the bucket. The jet must be minimally disturbed and spoiled by the contact of its free surface with the air. With this intention, a convergent nozzle is placed at the pipe outlet, which allows reducing the jet length between the orifice and the bucket.

The bucket, made out of bronze, $L_{a}=150 \mathrm{~mm}$ wide, is furnished with a handle, allowing it to be attached (via two axes) to the test bench frame (Fig. 3). The first axis (point $\Omega$ on Fig. 4(a)), located at the arm end, serves as the rotation axis for the entire wheel. The bucket rotation in reference to this axis defines the $\alpha$ incidence angle between the bucket and the jet. The second axis (measurement axis of the moment $M$ ) maintains the incidence angle. The bucket edge (hatched surface drawn on the Fig. $4(b)$ ) is situated in the xoy plane named $z_{0}$ plane. The yoz plane, perpendicular to the $z_{0}$ plane, is the symmetry plane of the bucket containing the bucket "splitter." The projection of the splitter on the oy-axis gives the $\mathrm{AB}$ segment, $103 \mathrm{~mm}$ long. A direct orthonormal reference frame $o x y z$ is defined, having for origin the middle point $\mathrm{O}$ of the $\mathrm{AB}$ segment. The $x o z$ plane is called the "reference plane." In order to have a progressive jet inlet flow, the bucket is truncated in the vicinity of point A. This zone constitutes the "cutout" of the bucket. The zone close to point B constitutes the

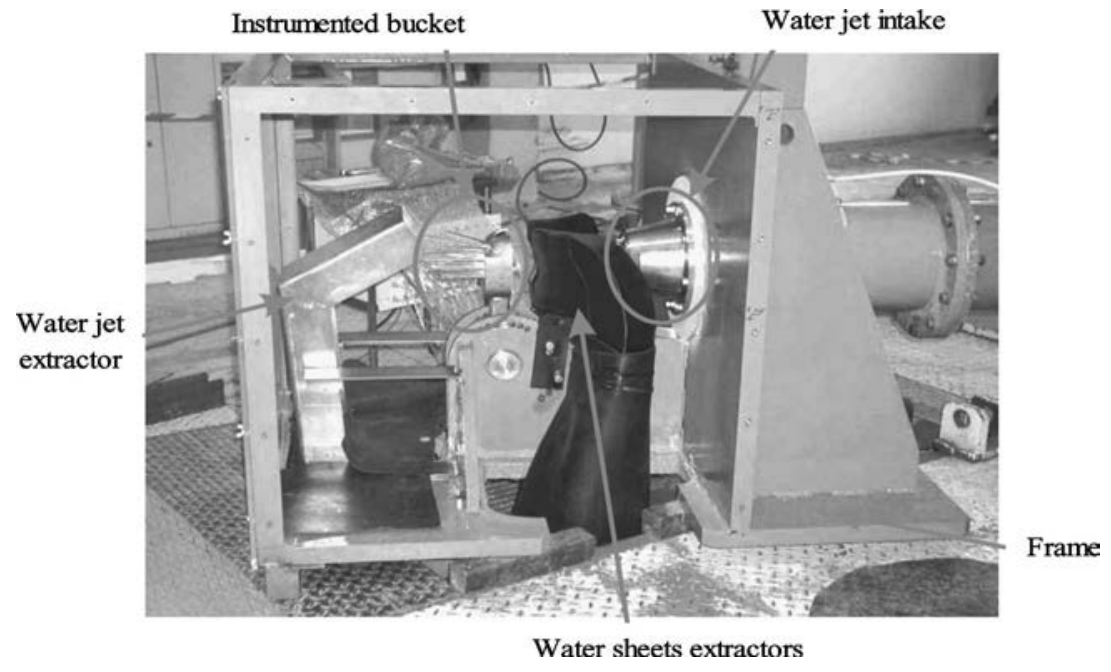

Fig. 2 Testing bench 


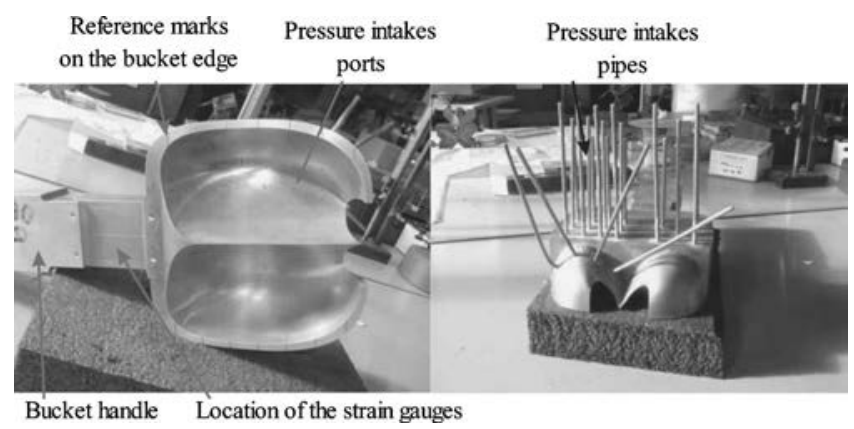

Fig. 3 Bucket experimental devices

"back part" of the bucket.

Three nondimensional numbers are classically used in the study of the flows within a Pelton turbine:

- The Reynolds number $\operatorname{Re}=\rho U D / \mu$, with $\mu$ water molecular viscosity equal to $1.002 \times 10^{-3} \mathrm{~kg} /(\mathrm{m} \mathrm{s})$. This number represents the ratio of the inertia forces with respect to the viscosity forces.
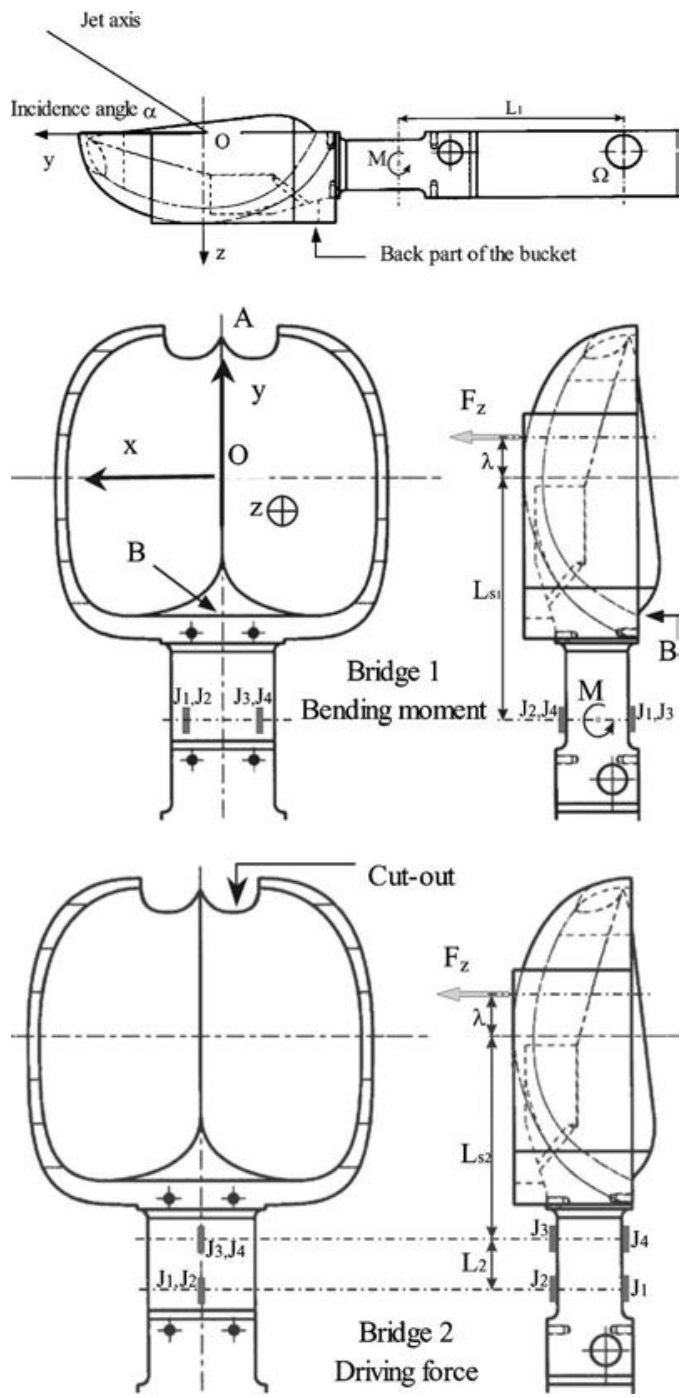

Fig. 4 Schematic views of the bucket

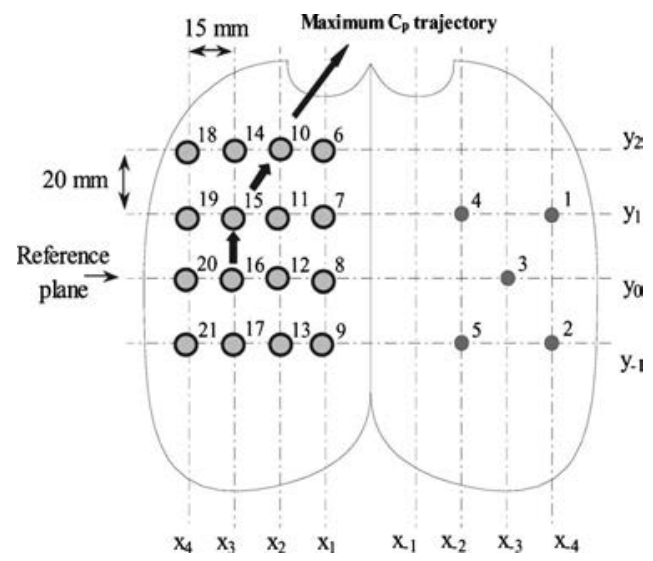

Fig. 5 Location of the pressure intakes

- The Froude number $\mathrm{Fr}=U / \sqrt{g L_{a}}$. This number represents the ratio of the inertia forces with respect to the gravitational forces.

- The Weber number $\mathrm{We}=\rho U^{2} L_{a} / \gamma$, with $\gamma$ water surface tension equal to $0.074 \mathrm{~N} / \mathrm{m}$. This number represents the ratio of the inertia forces with respect to the surface tension forces.

2.2 Pressure Measurement. The pressure $p_{i}$ is measured in 21 points of the wetted surface (inner surface) of the bucket arranged as indicated in Fig. 5. The five numbered pressure intakes $1-5$, located on the right half of the bucket, are the symmetrical ones of the five corresponding measurement points of the left part. These five measurement points are used to ensure the jet-centering control and the flow symmetry with respect to the bucket splitter. The intakes are placed at the points of a regular orthogonal network; the $x$-axis spacing is of $15 \mathrm{~mm}$ and the $y$-axis spacing of $20 \mathrm{~mm}$

To work these pressure intakes, the bucket is bored orthogonally on its surface. Fine pipes are welded on to the external surface in front of each orifice (Fig. 3); each tube is connected to the pressure transducer. Measurements of pressure are carried out using a double multiplexer (Scannivalve DSS, 24 channels) connected to a differential pressure transducer (Rosemount DP27). The instrument (Scannivalve) makes it possible to measure the pressure at the 21 points using a single pressure transducer. It operates as a barrel that connects the sensor with the pressure intakes, one after another. This device, requiring only one calibration, provides homogeneous measurement uncertainties. $H_{i}=\left(p_{i}\right.$ $\left.-p_{\text {atm }}\right) /(1 / 2) \rho U^{2}$ designates the measured relative pressure at point of index $i$, the unit of measurement being the water column meter (mCE).

2.3 Thrust and Torque Measurement. Measurements relate to the driving force Pelton $F_{z}$ (force creating the engine torque) and the bending moment $M_{w}$ with respect to the wheel axis (Fig. 4). The $F_{z}$ force is the component, perpendicular to the bucket handle, of the jet force exerted on the bucket. The force and the moment are measured using eight strain gages mounted on the bucket handle (Figs. $4(b)$ and $4(c)$ ). In order to increase the handle deformations, the gage region is intentionally weakened. Bridge 1 (Fig. 4(b)), made up of four unidirectional gages, measures the bending moment $M$. Bridge 2 (Fig. 4(c)), made up of four semiconductor gages assembled in a differential manner between two cross sections, measures the driving force $F_{z}$. The assembly per pair of gages, located on each side of the handle, allows one to eliminate by cancellation the deformations interference due to, for instance, dilation, radial force, or torsion. The measurement error, thus, comes primarily from the gage calibration and amplification 
Table 1 Measured magnitudes

\begin{tabular}{lcc}
\hline \hline Magnitudes & Instrumentation & $\begin{array}{c}\text { Relative } \\
\text { uncertainty }\end{array}$ \\
\hline Flow-rate $Q$ & Electromagnetic flow-meter or turbine flow-meter & $\pm 0,4 \%$ \\
Static head $H_{s}$ & Differential pressure transducer & $\pm 0,2 \%$ \\
Pressure $H_{i}$ & Differential pressure transducer + Scanivalve & $\pm 0,2 \%$ \\
Driving force $F_{z}$ and & Strain gages & $\pm 2,0 \%$ \\
Bending moment $M$ & & \\
\hline \hline
\end{tabular}

quality. The use of semiconductor gages provides, for bridge 2 , a relative error comparable to that of bridge 1 and equal to $\pm 2 \%$ (Table 1).

From $F_{z}$ and $M$ measurements, one deduces the moment $M_{w}$ and the shift $\lambda$ (distance between the origin of force and the reference plane) by the relations:

$$
M_{w}=M+F_{z} L_{1}=F_{z}\left(\lambda+L_{S 1}+L_{1}\right)
$$

$L_{1}=122 \mathrm{~mm}$ is the distance between the axis of the moment $M$ and the rotation axis. $L_{S 1}=121.7 \mathrm{~mm}$ is the distance between the axis of the moment $M$ and the reference plane. The Pelton diameter is then defined by $D_{P}=2\left(L_{S 1}+L_{1}\right)=487.5 \mathrm{~mm}$.

2.4 Experimental Tests. Table 1 indicates the relative uncertainties recorded for the measurements of the flow rate, static head, pressure, driving force, and the moment. The net head $H_{n}$, the orifice diameter $\phi_{d}$, and the incidence $\alpha$ are the three varying parameters.

Four diameters of the orifice were used: $\phi_{d}=38.1 \mathrm{~mm}$, $50.1 \mathrm{~mm}, 56.0 \mathrm{~mm}$, and $61.5 \mathrm{~mm}$. The incidence $\alpha$ varies from $60 \mathrm{deg}$ to $120 \mathrm{deg}$ in $10 \mathrm{deg}$ steps. The three chosen net heads are $H_{n}=30 \mathrm{~m}, 40 \mathrm{~m}$, and $50 \mathrm{~m}$. The corresponding velocities have the respective values: $U=24.26 \mathrm{~m} / \mathrm{s}, 28.01 \mathrm{~m} / \mathrm{s}$, and $31.32 \mathrm{~m} / \mathrm{s}$. For each couple of values (orifice diameter-incidence), Table 2 indicates the tested net heads, the total number of tests being 56. Table 3 indicates the mean volume flow rate measured (liters per second) for the three net heads and the four diameters of the orifice. Because of the jet contraction, the orifice $\phi_{d}$ is higher than the jet diameter $D$. The jet diameter, flow rate, and net head are bound by the relation $D=\sqrt{4 Q / \pi \sqrt{2 g H_{n}}}$. For the whole of the tests (Table 3 ), the Reynolds number $\operatorname{Re}$ is included in values $3.6 \times 10^{6}$ to $4.7 \times 10^{6}$. In consideration of high values of the Reynolds number,

Table $2 H_{n}$ head values. Total of 56 tests

\begin{tabular}{lcccc}
\hline \hline$\alpha$ deg & $\phi_{\mathrm{d}}=38.1 \mathrm{~mm}$ & $\phi_{\mathrm{d}}=50.1,1 \mathrm{~mm}$ & $\phi_{\mathrm{d}}=56 \mathrm{~mm}$ & $\phi_{\mathrm{d}}=61.5 \mathrm{~mm}$ \\
\hline $60 \mathrm{deg}$ & & $30-50 \mathrm{~m}$ & $30-50 \mathrm{~m}$ & $30-50 \mathrm{~m}$ \\
$70 \mathrm{deg}$ & & $30-50 \mathrm{~m}$ & $30-50 \mathrm{~m}$ & $30-50 \mathrm{~m}$ \\
$80 \mathrm{deg}$ & $30-40-50 \mathrm{~m}$ & $30-40-50 \mathrm{~m}$ & $30-40-50 \mathrm{~m}$ & $30-40-50 \mathrm{~m}$ \\
$90 \mathrm{deg}$ & $30-40-50 \mathrm{~m}$ & $30-40-50 \mathrm{~m}$ & $30-40-50 \mathrm{~m}$ & $30-40-50 \mathrm{~m}$ \\
$100 \mathrm{deg}$ & $30-50 \mathrm{~m}$ & $30-50 \mathrm{~m}$ & $30-50 \mathrm{~m}$ & $30-50 \mathrm{~m}$ \\
$110 \mathrm{deg}$ & & $30-50 \mathrm{~m}$ & $30-50 \mathrm{~m}$ & $30-50 \mathrm{~m}$ \\
$120 \mathrm{deg}$ & & $30-50 \mathrm{~m}$ & $30-50 \mathrm{~m}$ & $30-50 \mathrm{~m}$ \\
\hline \hline
\end{tabular}

Table 3 Mean volume flow rate $Q$, inlet velocity $U$, Reynolds number $\mathbf{R}_{e}$

\begin{tabular}{lcccc}
\hline \hline D* & $\begin{array}{c}\phi_{d} \\
(\mathrm{~mm})\end{array}$ & $\begin{array}{c}H_{n}=30 \mathrm{~m} \\
Q(1 / \mathrm{s})\end{array}$ & $\begin{array}{c}H_{n}=40 \mathrm{~m} \\
Q(1 / \mathrm{s})\end{array}$ & $\begin{array}{c}H_{n}=50 \mathrm{~m} \\
Q(1 / \mathrm{s})\end{array}$ \\
\hline 5.07 & 38.1 & 16.7 & 19.3 & 21.5 \\
3.84 & 50.1 & 29.1 & 33.6 & 37.5 \\
3.44 & 56.0 & 36.2 & 41.8 & 46.8 \\
3.13 & 61.5 & 43.8 & 50.5 & 56.5 \\
Inlet velocity $U$ & & $24.3 \mathrm{~m} / \mathrm{s}$ & $28.0 \mathrm{~m} / \mathrm{s}$ & $31.3 \mathrm{~m} / \mathrm{s}$ \\
Reynolds number $\mathrm{R}_{e}$ & $3.6 \times 10^{6}$ & $4.2 \times 10^{6}$ & $4.7 \times 10^{6}$ \\
\hline \hline
\end{tabular}

the contraction coefficient of the jet is constant; consequently, for a fixed value of the orifice diameter (or jet diameter) the ratio $Q / \sqrt{H_{n}}$ remains the same one. The values of the diameter $D$ are obtained with a relative error of $2.5 \%$. The usual nondimensional magnitude $D^{*}$ indicated in Table 3 is defined by $D^{*}=L_{a} / D$.

2.5 Flow Visualization (Fig. 6). The photographs are taken with a numerical camera provided with a flash. A droplets fog is always present in the enclosure. It is accentuated when the head or the jet diameter increases. No particular effect of the head on the flow in the bucket was noted. For this reason, the photographs were made in the case of a slight head, so one reaches the maximum quality.

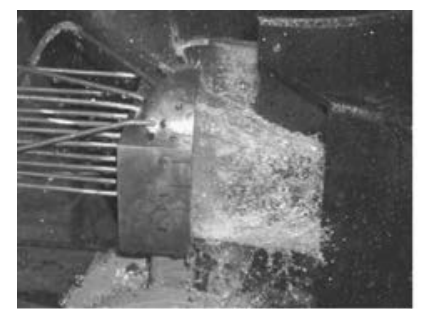

6.1) $\phi_{\mathrm{d}}=38,1 \mathrm{~mm}\left(\mathrm{D}^{\circ}=5,07\right) \alpha=90^{\circ}$

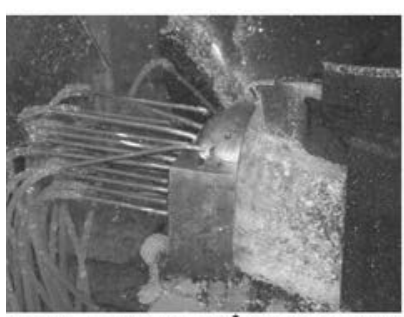

6.2) $\phi_{\mathrm{d}}=50,1 \mathrm{~mm}\left(\mathrm{D}^{*}=3,84\right) \alpha=90^{\circ}$
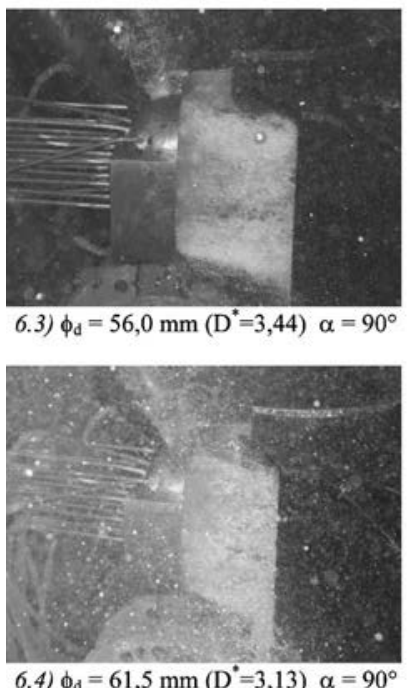

6.4) $\phi_{\mathrm{d}}=61,5 \mathrm{~mm}\left(\mathrm{D}^{\circ}=3,13\right) \alpha=90^{\circ}$

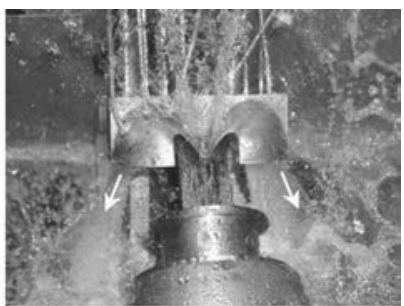

6.5) $\phi_{\mathrm{d}}=50,1 \mathrm{~mm}\left(\mathrm{D}^{\circ}=3,84\right) \alpha=60^{\circ}$

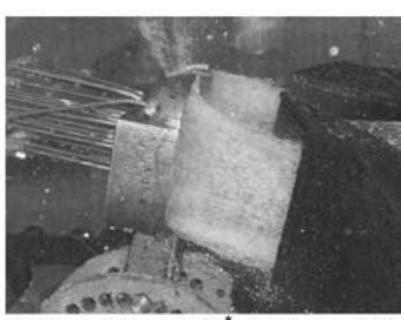

6.6) $\phi_{\mathrm{d}}=50,1 \mathrm{~mm}\left(\mathrm{D}^{*}=3,84\right) \alpha=80^{\circ}$
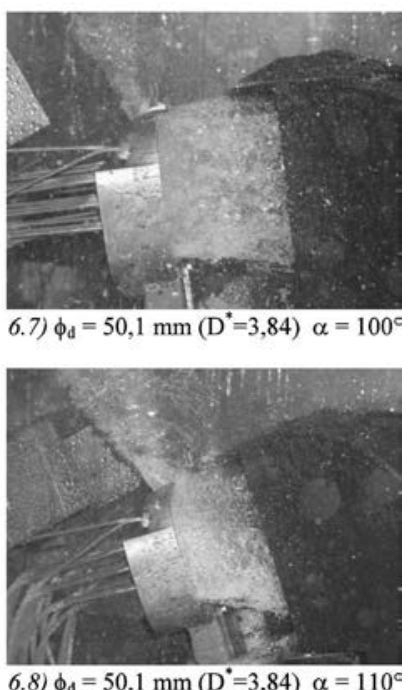

6.8) $\phi_{\mathrm{d}}=50,1 \mathrm{~mm}\left(\mathrm{D}^{\circ}=3,84\right) \alpha=110^{c}$
Fig. 6 Different side and top views of the sheets of water 
The first panel of Fig. 6 presents the flow obtained with an orifice of $38.1 \mathrm{~mm}$ and an incidence of $90 \mathrm{deg}$. After jet impact in the bucket occurs, the flow at the exit of the bucket turns into a sheet. These sheets of water appear of a white and opaque color, typical of an air-water mixture. Furthermore, downstream the bucket, the sheets of water break up in droplets. At the bucket exit, the streamlines deviation angles are more significant at the ends (back part and cutout) than in the vicinity of the reference plane. This phenomenon involves the contraction of the sheets downstream the bucket. The fifth panel of Fig. $6\left(\phi_{d}=50.1 \mathrm{~mm}\right.$ and $\alpha=60 \mathrm{deg}$ ) presents a top view of the flow, the white arrows indicating the various directions of the sheet of water at exit of bucket. The various photographs of Fig. 6 highlight the water quantities leaving by the cutout. This phenomenon was observed in the various configurations obtained while varying the orifice diameter and the incidence angle. Images one to four in Fig. 6 correspond to different jet diameters for an incidence fixed at $90 \mathrm{deg}$. The fluid enters entirely in the bucket. It is observed that the cutout leakage flow rate increases with the diameter.

Images five to eight in Fig. 6 correspond to different angles of incidence for an orifice diameter $\phi_{d}$ fixed at $50.1 \mathrm{~mm}$. Let us note that, for incidence $\alpha=60 \mathrm{deg}$, all of the jet does not enter into the bucket. The part of the jet that does not come into the bucket is expelled outside the Pelton wheel. Beyond $80 \mathrm{deg}$, the jet enters entirely into the bucket. A part of the jet, strongly increasing with the incidence, leaves the bucket by the cutout while having covered only a small distance inside it. In all cases, a leakage flow rate is noted at the cutout.

2.6 Net Head Effect on Pressure. The pressure coefficient is given by $C_{p}=\left(p-p_{\text {atm }} /(1 / 2) \rho U^{2}\right)=H_{i} / H_{n}$. For the 16 pressure intakes (points 6-21), the measurement of the pressure coefficient was realized for each of the three net heads. No significant variation of the pressure coefficient is noted with the net head. As an example, for a jet diameter $D^{*}=3.44$ and an incidence angle of $90 \mathrm{deg}$, the maximum relative gap is $<0.1 \%$. As a result, in the following, the results are presented only for $H_{n}=30 \mathrm{~m}$.

2.7 Symmetry Checking. The symmetry of the flow relative to the yoz plane was checked for the paired numbered points: $(1,19),(2,21),(3,16),(4,11)$, and $(5,13)$. The measurements show that, for the incidence angle of value $90 \mathrm{deg}$, the pressures symmetry is realized. For these five points, the maximum relative gap is $<0.8 \%$.

\section{Numerical Study}

The numerical study was conducted in the laboratory of LEGI (Grenoble, France). The software used is FluENT. The NavierStokes solver solves the mean equations of turbulence (RANS).

To represent the two-phase flows, there are Eulerian methods and Lagrangian methods [17]. The first consists of assuming each phase as continuous. Information between phases is carried by interface conditions. The second assumes that one of the phases (water) disperses itself in the other (air). Within the framework of this study, the Eulerian methods are well adapted. The free surface is then modeled using a multifluid model or a homogeneous twophase model or a volume of fluid (VOF) method. The multifluid model is a complete and precise model but requires much computing time. The homogeneous model is rather used for flows where one of the phases is uniformly distributed in the other, such as the flows with bubbles. Under the present configuration the VOF method is completely appropriate [18]. It consists of representing the fluid volume by the water volume fraction $\chi$. The value of $\chi$ is 1 when the cell is filled with water and 0 when the cell is empty. The determination of $\chi$ requires an additional equation, thus, the advection equation of the fluid. The free surface is the set of points for which the volume fraction is equal to $\chi_{0}, \chi_{0}$ being included in values 0 to 1 .

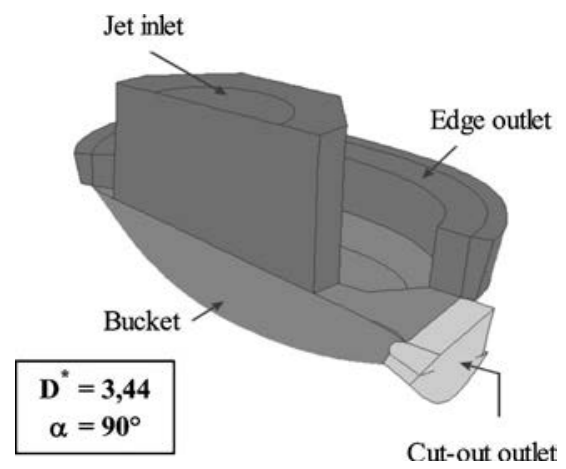

Fig. 7 Diagram of the calculation blocks

The studied cases correspond to seven jet diameters with an incidence fixed at $\alpha=90 \mathrm{deg}$ and to seven incidences with a jet diameter fixed at $D^{*}=3.44$. The range of diameters used at the time of the experimental study was supplemented by three additional ones: $D^{*}=5.91,4.39,2.90$. The incidences are identical to the experimental ones.

3.1 Numerical Modeling. A preliminary study was initially performed concerning the $2 \mathrm{D}$ and $3 \mathrm{D}$ jets impact on a flat plate. The major objective was to evaluate the abilities of the FLUENT VOF model. The numerical results were compared to analytical results for the $2 \mathrm{D}$ and experimental results for the $3 \mathrm{D}$. The comparisons with regard to the sheet of water thickness and the pressure are excellent [14].

3.1.1 Discretization. The simulation of the flow in the bucket requires the setting of the control volume, the boundary conditions, and the 3D mesh. Because of the flow symmetry relative to yoz plane, only the space of a half bucket geometry is considered. Figure 7 illustrates the composition of the control volume. It consists of four parts: the jet inlet domain, the bucket, the edge, and the cutout. This partition makes it possible to modify only the jet inlet domain when incidence is changed. The inlet domain is built in order to include all of the jet whatever the diameter value. For each case, the jet inlet face is taken parallel to the reference plane. Consequently, the jet inlet border is a half circle for $\alpha=90 \mathrm{deg}$ and a half ellipse for the other incidences. This face is located at $50 \mathrm{~mm}$ above the reference plane. The outlet region of the bucket edge is $20 \mathrm{~mm}$ high above $z_{0}$ plane (red zone in Fig. 7).

The boundary conditions are a zero velocity condition on the bottom and the edge of the bucket, a symmetry condition on the faces belonging to the symmetry plane, a uniform velocity condition on the jet inlet face, and a constant pressure condition for all the faces in contact with the air.

The mesh construction required a preliminary study in order to determine the type and the density of cells to be used. A maximum $3 \mathrm{~mm}$ size of the cells stabilizes the results in comparison to the refinement of the mesh. Table 4 shows that, for a number of cells higher than 180,000, the thrust and torque become insensitive with the cell numbers. For all the treated cases, a number of cells approximately equal to 300,000 corresponds to the criterion of the maximum size as well as the numerical stability.

The cells constituting the hybrid mesh are hexahedral, tetrahe-

Table 4 Numerical stability test

\begin{tabular}{lcc}
\hline \hline Cells number & $\begin{array}{c}\text { Thrust } F_{z} \\
(\mathrm{~N})\end{array}$ & $\begin{array}{c}\text { Torque } M_{w} \\
(\mathrm{Nm})\end{array}$ \\
\hline 37,500 & 1178 & 289 \\
94,500 & 1188 & 291 \\
183,000 & 1189 & 293 \\
342,000 & 1189 & 293 \\
\hline \hline
\end{tabular}



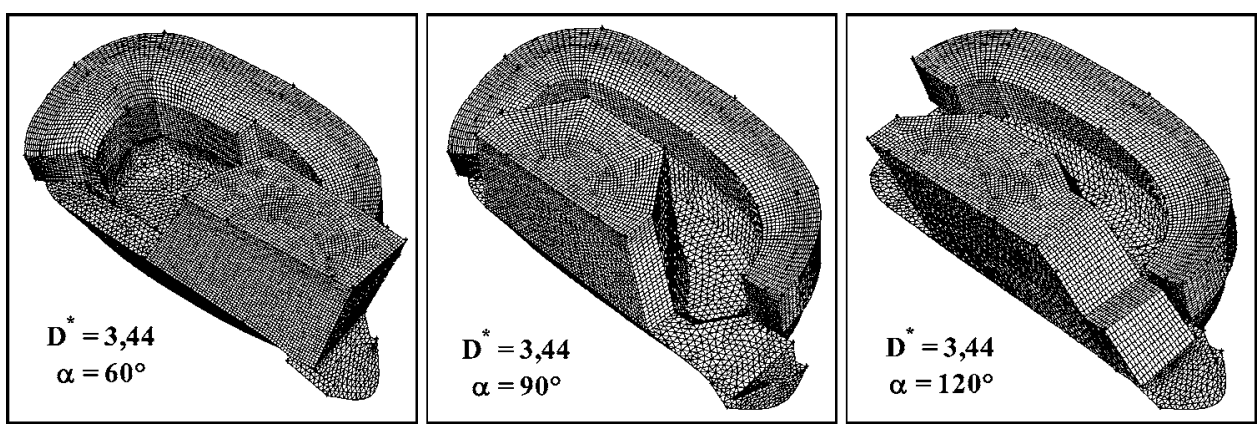

Fig. 8 View of the meshes

dral, or pyramidal in shape. The pyramidal cells allow the connection between domains meshed with the two other types of cells. The jet inlet face is paved in a nonstructured way with quadrilaterals. The inlet domain mesh (blue block) is built using the Cooper method. The domain relative to the cutout outlet is meshed with tetrahedrons. Figure 8 illustrates the meshes obtained for a fixed diameter for three cases of incidence.

3.1.2 Calculation Parameters. The Navier-Stokes equations are discretized by a finite volumes method. The discretization scheme used to model the fluid advection is of the second order, upstream centered. The free surfaces are characterized by the volume fraction value $\chi_{0}=0.5$. The PLIC method (piecewise linear interface calculation) [19] is used for the geometrical reconstruction of the interface. Turbulence is taken into account using the $k-\varepsilon$ standard model with wall functions. On the jet inlet face the $k$ and $\varepsilon$ values are expressed according to the mean characteristics of the flow, namely, turbulence intensity and characteristic length. The turbulence intensity is taken equal to $5 \%$ and the characteristic length to the jet diameter value.

A 3D boundary layer calculation [20] carried out on the bucket with a 90 deg jet incidence highlights that the viscosity forces are very weak compared to the inertia forces. Compared to the $2 \rho Q U$ value of the ideal force, the three components of the viscous force have the following values: $0.26 \%$ on the $x$-axis, $0.02 \%$ on the $y$-axis, and $-0.3 \%$ on the $z$-axis. Considering these values, in a first stage, a laminar calculation has been performed. In this case, numerical instabilities occur. These instabilities do not originate from the near-wall region but are due to the strong velocity gradients close to the interface (air entrainment due to the water motion). The use of a turbulence model considerably reduces these gradients and, thus, stabilizes the calculation. Consequently, the modeling of the boundary layer and the refinement of the grid near the wall are not really necessary. The values of the dimensionless near wall distance $Y^{+}$are between 250 and 600, and the minimum value of the velocity at the first node of the wall is $\sim 13 \mathrm{~m} / \mathrm{s}$ compared to the $25 \mathrm{~m} / \mathrm{s}$ value of the jet velocity. It is significant to note that, for the mesh used, FLUENT calculation gives viscous forces about those given by the 3D boundary layer calculation, namely: $1 \%$ on the $x$-axis, $0.04 \%$ on the $y$-axis, and
$0.4 \%$ on the $z$-axis. Finally, the resolution of the viscous flow is not optimal, but it is of no importance because the viscous effects are very weak. This is confirmed by the good comparison between the numerical and experimental pressures (see Fig. 14).

Carried-out calculations are unsteadily converging toward a steady state. Time integration is performed using the implicit Euler method of the second order. The two numerical criteria of convergence are the stabilization of the force exerted by the jet on the bucket and the equality of the inflow and outflow values. It takes $\sim 35 \mathrm{~h}$ of time consumption (bi-processor PC AMD Athlon $2000+)$ to perform the 4500 time steps required to insure the convergence.

The present experimental configurations allow neglecting the force of gravity compared to the force of pressure. Indeed, according to Table 3, minimum velocity of the jet is $\sim 24 \mathrm{~m} / \mathrm{s}$, which gives a minimum Froude number of 24 . In the same way, the surface tension effects are neglected (the minimum Weber number is equal to $1.2 \times 10^{6}$ ).

\subsection{Numerical Results and Comparison}

3.2.1 Fixed Angle of Incidence $(\alpha=90 \mathrm{deg})$. Figure 9 shows the free surface in the case of three experimental jet diameters. Inside the bucket, the wetted surface increases with the jet diameter. The thickness of the outgoing sheet of water (at the bucket edge level) increases back and forwards except for the largest diameter $\left(D^{*}=3.13\right)$, for which the sheet of water is thinner in the reference plane area than at the bucket ends. No water leakage flow through the cut-out is noted except for the case where $D^{*}$ $=3.13$. For the three studied diameters, the experimental tests reveal a low leakage at the cutout outlet (Fig. 6).

In the reference plane, Fig. 10 shows the water thickness. Inside the bucket, the water thickness $e$, measured according to the bucket normal, is defined as the distance from a point of the bucket surface to the free face. This distance nondimensionalized with respect to the bucket width is given by: $e^{*}=e / L_{a}$. The nondimensional curvilinear abscissa $s^{*}$ is worth 0 for the splitter point and 1 for the edge point. For the lowest jet diameters the water thickness decreases regularly inside the bucket. A water accumulation around the common value $s^{*}=0.60$ appears only when $D^{*}$
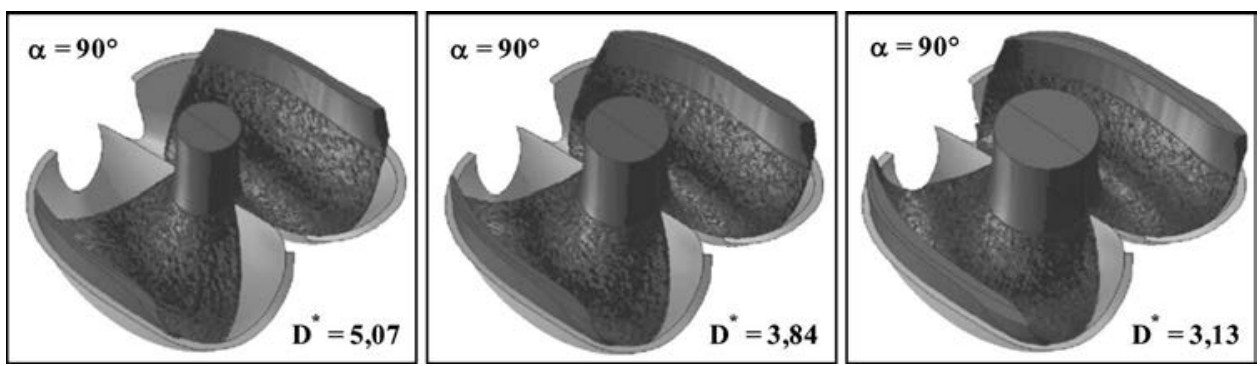

Fig. 9 Free surface of the jet 


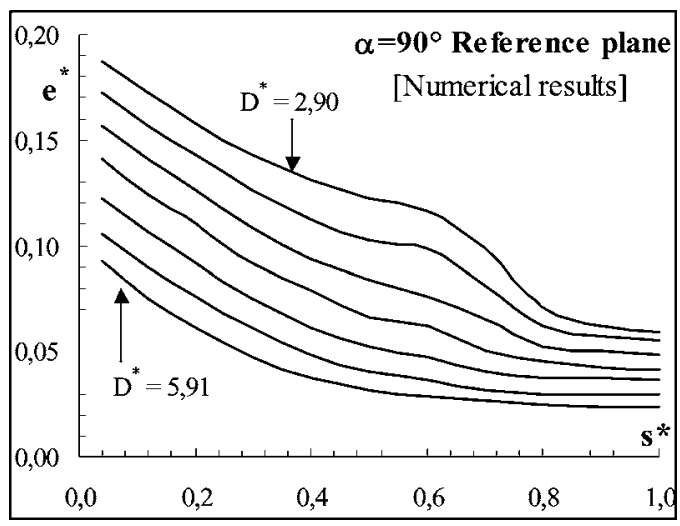

Fig. 10 Thickness of the sheet of water in the reference plane

$<3.84$. It is characterized by a stage that becomes more and more clear as the jet diameter increases. This phenomenon is related to the overpressure in the bucket bottom, which causes a velocity reduction in the sheet of water core and consequently increases its thickness.

Figure 11 illustrates a cartography of the pressure coefficient $C_{p}$ (on the left) and of the water volume fraction $\chi$ (on the right). The three presented cases correspond to the three cases of Fig. 9. The zone having the strongest pressures $\left(C_{p} \sim 0.9\right)$ is located in the bucket bottom and shifted toward the edge. This zone extends when the jet diameter increases. That is in agreement with the pressure effects (on the sheet of water thickness) as previously commented.

3.2.2 Fixed Diameter $\left(D^{*}=3.44\right)$. Figure 12 illustrates the water distribution inside the bucket for three incidences. For $\alpha$ $=60 \mathrm{deg}$, water spreads out over most of the inner surface and concentrates on the back edge at the bucket exit. Part of the jet does not penetrate inside the bucket: the corresponding water quantity does not act on the bucket. For $\alpha=90 \mathrm{deg}$, the sheet of water extends toward the cutout edge and becomes thinner. The entire jet enters the bucket and the entire sheet of water is contained in the bucket. For $\alpha=120 \mathrm{deg}$, the sheet of water is particularly wide along the bucket edge. A significant part of the jet goes out of the cutout, which implies, for this case, a significant loss of force.

The experimental views in Fig. 6 confirm, qualitatively, to the preceding numerical results. One, however, notes in this figure that, whatever the diameter and incidence, there is always a quantity of more or less significant water that vacates through the

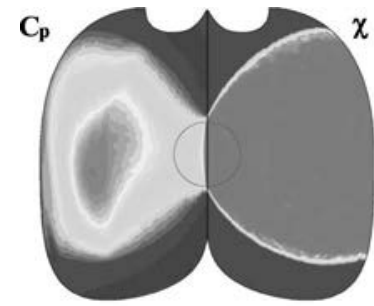

$D^{*}=\mathbf{5 , 0 7}$
$\mathrm{C}_{\mathrm{p}}$

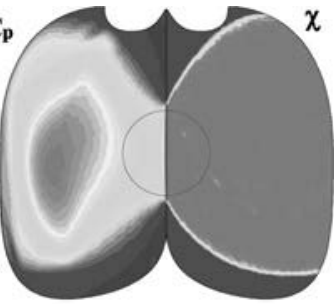

$D^{*}=3,84$

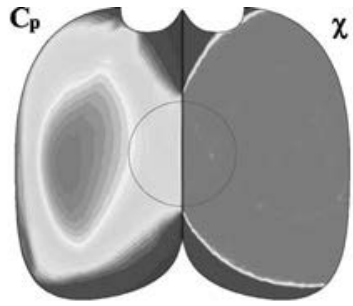

$\mathrm{D}^{*}=\mathbf{3 , 1 3}$

$\begin{array}{llllll}x & 0,00 & 0,25 & 0,50 & 0,75 & 1,00\end{array}$

$\begin{array}{lllllllll}C p & 0,00 & 0,15 & 0,30 & 0,45 & 0,60 & 0,75 & 0,90\end{array}$

$\alpha=90^{\circ}$

Fig. 11 Pressure coefficient and water volume fraction
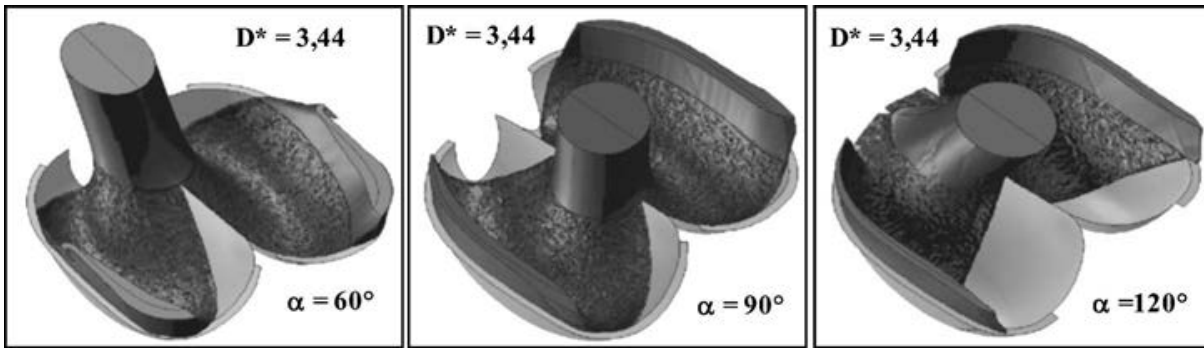

Fig. 12 Free surface of the jet

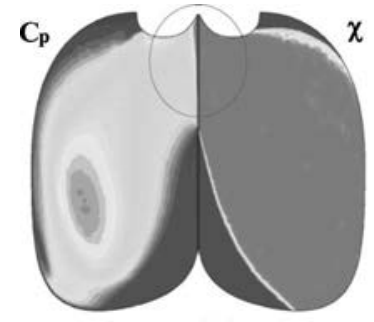

$\alpha=60^{\circ}$

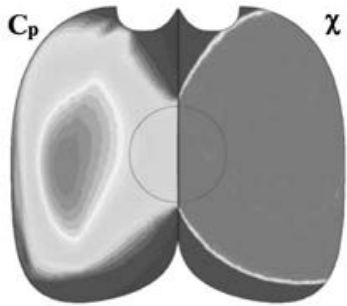

$\alpha=90^{\circ}$

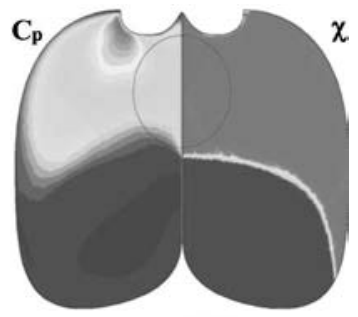

$\alpha=120^{\circ}$

$\begin{array}{llllll}x & 0,00 & 0,25 & 0,50 & 0,75 & 1,00\end{array}$

$\begin{array}{clllllll}C p & 0,00 & 0,15 & 0,30 & 0,45 & 0,60 & 0,75 & 0,90\end{array}$

$D^{*}=3,44$

Fig. 13 Pressure coefficient and water volume fraction 

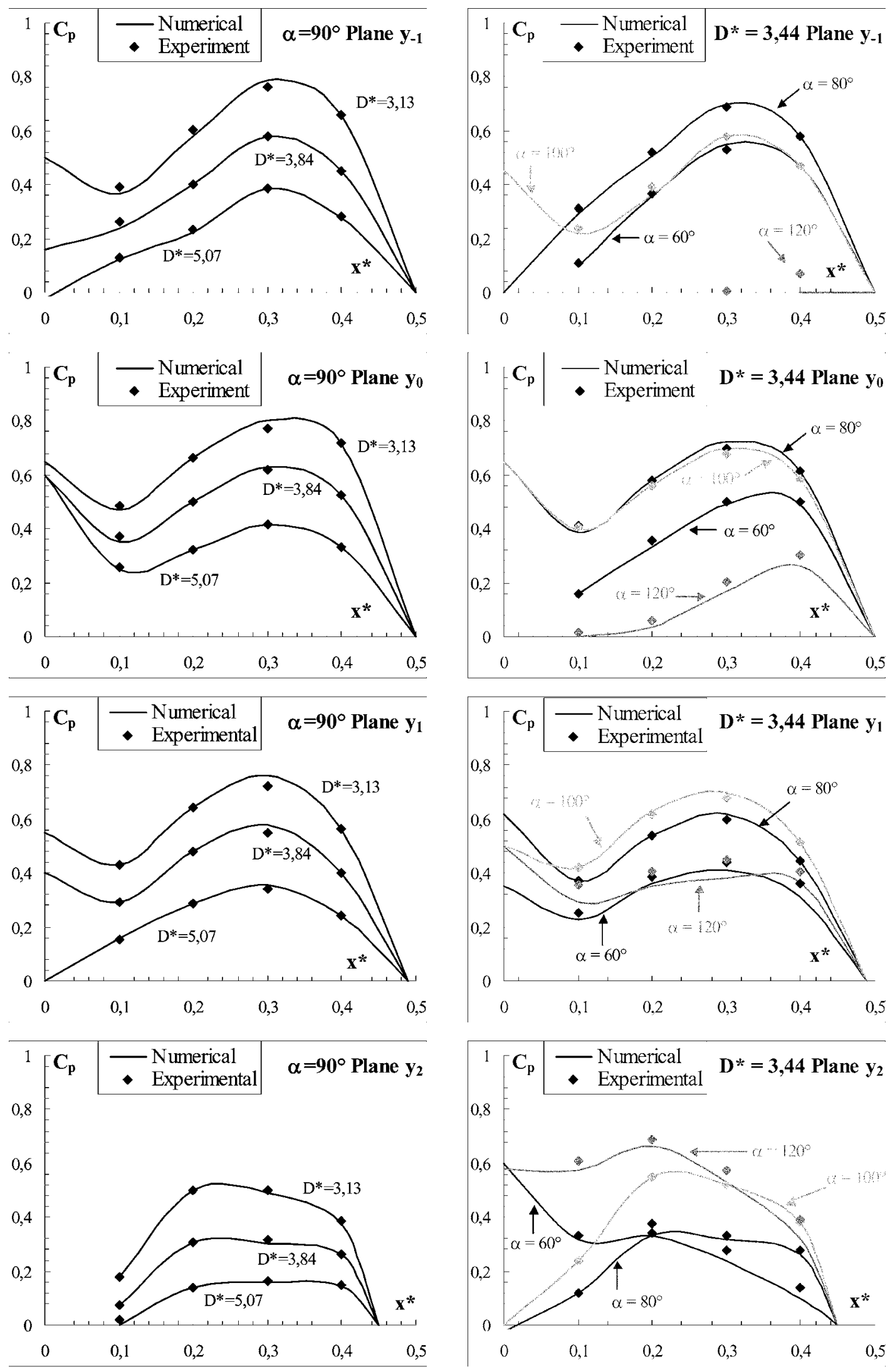

Left-hand column

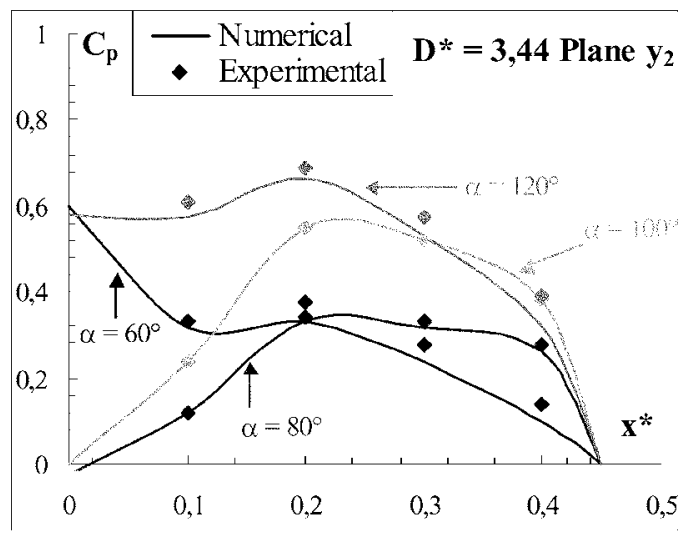

Right-hand column

Fig. 14 Pressure coefficient: numerical and experimental results 


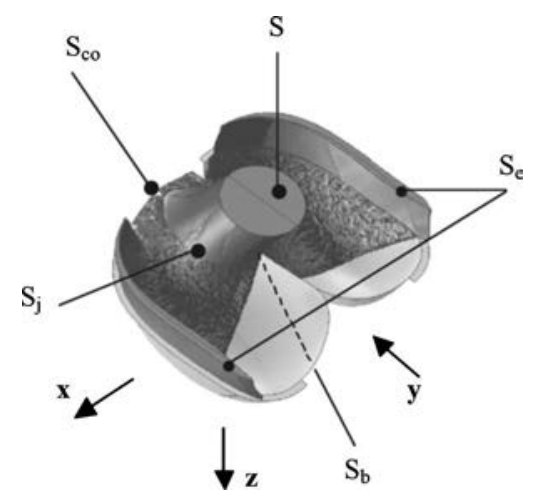

Fig. 15 Schematic view of the boundary surfaces

cutout.

Figure 13 represents the pressure field corresponding to the three previous cases. One notes, in conformity with the experimental results, the displacement of the overpressure zone toward the cutout when the incidence increases. Under the case of the $120 \mathrm{deg}$ incidence, a significant nonwetted zone is localized near the rear of the bucket.

3.2.3 Comparison of the Measured and Calculated Magnitudes. Figure 14 presents the experimental and numerical pressure coefficients in the planes $y_{-1}, y_{0}, y_{1}$, and $y_{2}$ indicated on Fig. 5. The four figures in the left-hand column are related to the case of incidence $\alpha=90 \mathrm{deg}$. Each figure presents the three jet diameter values: $D^{*}=3.13,3.84$, and 5.07. The four figures of the right-hand column are related to the case of jet diameter $D^{*}$ =3.44. Each figure presents four incidence values: $\alpha=60 \mathrm{deg}$, $80 \mathrm{deg}, 100 \mathrm{deg}$, and $120 \mathrm{deg}$. The experimental points and the corresponding numerical curves have the same color.

The agreement of the results with numerical calculations is very good. However, small deviations appear for the points of planes $y_{1}$ and $y_{2}$ under the case of the two extreme incidences $60 \mathrm{deg}$ and $120 \mathrm{deg}$. These are the two incidences for which a nonnegligible quantity of fluid goes out through the cutout and for which the flow undergoes the most significant change of direction close to the cutout.

With the incidence fixed at $90 \mathrm{deg}$ (curves on the left side), it is clear that the pressure increases with the diameter. In the planes $y_{-1}, y_{0}$, and $y_{1}$, the maximum pressure is around the nondimensional abscissa $x^{*}=0.3$ and in the plane $y_{2}$ around $x^{*}=0.2$. These points are situated in the deepest zone of the bucket. In each plane, no shape variation of the curves is noted by changing the diameter. In the plane $y_{2}$, the noted pressure deficit comes from the proximity of the cutout.

Concerning the total force, the momentum theorem is applied to the closed fluid domain illustrated in Fig. 15. This domain consists of the following boundary surfaces:

- the crosssection $S$ of the jet inlet.

- the free surface $S_{j}$ of the jet.

- the wetted surface $S_{\mathrm{b}}$ located inside the bucket.

- the surface $S_{e}$, obtained by the intersection of the sheet of water and a plane parallel with the $z_{0}$ plane. This section is located at an external vicinity of the bucket edge.

- the surface $S_{c o}$, obtained by the intersection of the sheet of water and a plane perpendicular to the unit vector $\boldsymbol{n}$. The vector $\boldsymbol{n}$ is directed outside the domain and contained in the symmetry plane (yoz plane). The direction $n$ is selected so that all of the water exiting through the cutout crosses the plane. In almost all configurations, the choice of the direction $\boldsymbol{n}$ parallel with the direction $\boldsymbol{y}$ is sufficient to ensure the previous condition. This section is located at an external vicinity of the cutout.
When projecting on the $z$-axis-examining the force exerted by the bucket interior on the fluid-one obtains the expression for the Pelton driving force

$$
F_{z}=\rho Q U \sin \alpha+\iint_{S_{e}} \rho V_{z}^{2} d S+\iint_{S_{c o}} \rho V_{n}^{2} d S
$$

$Q=U S$ is the flow rate through a jet section. $V_{z}$ and $V_{n}$, respectively, indicate the velocity components according to the $z$-axis and direction $\boldsymbol{n}$. The maximum force is obtained for the ideal case. This case corresponds to a bucket that would force the streamlines, at exit, to be perpendicular to the $z_{0}$ plane and without velocity loss. In fact, the exit velocity on surface $S_{e}$ is equal to $U$, which gives the following maximum force:

$$
F_{z \max }=\rho Q U(1+\sin \alpha)=\frac{\pi}{2} \rho g D^{2} H_{n}(1+\sin \alpha)
$$

The nondimensional driving force is defined by $F_{z}^{*}=F_{z} / F_{z \max }$. In order to give a practical evaluation of the loss of force on an actual bucket compared to an ideal bucket, one introduces the relative loss of thrust $\Delta F_{z}^{*}=\left(F_{z \max }-F_{z}\right) / F_{z \max }=1-F_{z}^{*}$. This equation represents the relative difference between the force generated by the flow and that which this flow, in the ideal case, would have produced. By using the relation (2) the relative loss of thrust is written as the sum of the loss due to the edge and the loss due to the cutout

$$
\begin{gathered}
\Delta F_{z}^{*}=\left[\Delta F_{z}^{*}\right]_{\text {Edge }}+\left[\Delta F_{z}^{*}\right]_{\text {Cutout }} \\
{\left[\Delta F_{z}^{*}\right]_{\text {Edge }}=\frac{-1}{S(1+\sin \alpha)} \iint_{S_{e}} \frac{V_{z}}{U}\left(1+\frac{V_{z}}{U}\right) d S} \\
{\left[\Delta F_{z}^{*}\right]_{\text {Cutout }}=\frac{1}{S(1+\sin \alpha)} \iint_{S_{c o}} \frac{V_{n}}{U}\left(1+\frac{V_{z}}{U}\right) d S}
\end{gathered}
$$

In a similar way, the moment $M_{w}$ relative to the wheel axis is nondimensionalized with respect to the value $M_{w \max }$ corresponding to the ideal case. In this case, the shift $\lambda$ is taken equal to zero, which provides $M_{w \max }=\left(D_{P} / 2\right) F_{z \max }$. The moment relative to the measurement axis is defined by $M^{*}=M / M_{w \max }$.

Figures $16(a)$ and $17(a)$ present respectively the torque $M^{*}$ and the thrust $F_{z}^{*}$ versus the incidence angle of the bucket for a medium jet size $D^{*}=3.44$. A good agreement between the numerical and experimental results is noted. It is observed that the maximum thrust is obtained at $90 \mathrm{deg}$ and maximum torque at $110 \mathrm{deg}$. This is due to the maximum pressure displacement toward the cutout when incidence exceeds 90 deg (cf. Sec. 2.2, Fig. 5).

Below $80 \mathrm{deg}$, the experimental torque and thrust decrease regularly, although numerical ones present a plateau and then decrease strongly. These discrepancies can be explained as following. Between $70 \mathrm{deg}$ and $80 \mathrm{deg}$, the numerical calculation underestimates the leakage flow exiting the cutout. This is highlighted by Fig. 18. Consequently, the thrust and torque experimental losses due to the cutout leakage flow are higher than the corresponding numerical losses. In this case, the strong curvature of streamlines and the water sheet thinness are difficult to model.

Let us note that, above $80 \mathrm{deg}$, when the incidence increases, these differences tend toward zero in spite of the growth of the cutout leakage flow. In this case, the sheets of water that leave the cutout become increasingly thick and have increasingly small curvatures. Thus, numerical calculation provides a very good approximation of the actual flow.

Below $70 \mathrm{deg}$, the previous experimental analysis shows that a part of the jet does not enter in the bucket (Fig. 6) and flows close to its rear. This flow, probably creates a low-pressure zone that contributes to a torque and thrust increase. This effect has been demonstrated on rotating bucket calculations by Zoppé [14] and Mack [13]. Because the rear zone is not considered in the present 

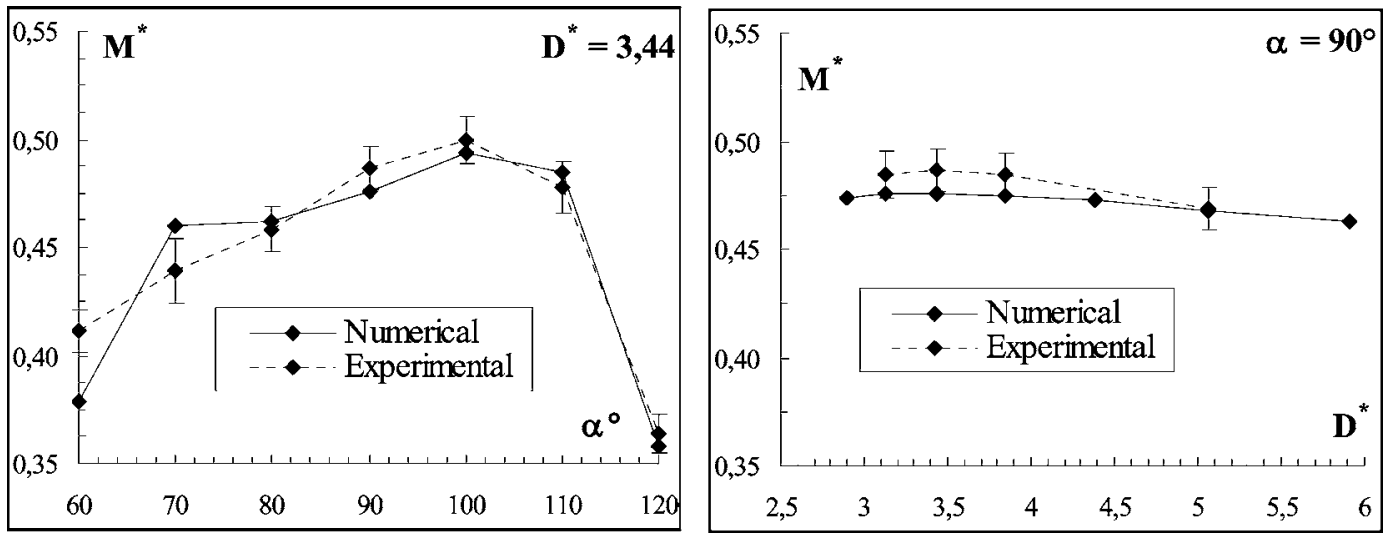

Fig. 16 Total torque

modeling, this mechanism is not predicted. Thus, the torque and thrust values provided by calculation are smaller than the experimental ones.

Figures $16(b)$ and $17(b)$ show torque and thrust variations versus the jet size $D^{*}$ for a jet incidence $\alpha=90 \mathrm{deg}$. Numerical and experimental values fit very well. Both the torque and thrust values are maximum near $D^{*}=3.44$. This value matches approximately the optimum jet size of the corresponding Pelton turbine.

Figures 19(a) and 19(b) show the deficit of thrust (compared to an ideal bucket) for the jet size and incidence variations, respectively. On each figure, the contributions of the edge and the cutout (relation (4)) are presented. In Fig. 19(a), the edge loss presents a minimum equal to 0.06 at the $100 \mathrm{deg}$ value of incidence and never exceeds 0.105 . The cutout loss begins below $80 \mathrm{deg}$ and above $90 \mathrm{deg}$, and increases strongly. This behavior confirms the previous analysis on the flow-rate loss close to the cutout.

In Fig. 19(b), at the $90 \mathrm{deg}$ fixed $\alpha$ value, the cutout losses occur only for the large jet diameters though they always exist in the experiments (see Fig. 6). The edge losses decrease with $D^{*}$. For the smaller jets (higher $D^{*}$ ), this decrease is attributed to an increase of the outlet mean velocity at the edge. This is a typical viscous effect [14].

For the larger jets $\left(D^{*}<3.44\right)$, the edge loss becomes nearly constant. This last tendency is explained by the kinematic deviation of the fluid compared to the edge bucket. In order to evaluate this deviation, one considers, in projection in the reference plane, the angle between the velocity vector and the plane tangential to the bucket surface at the edge. In the case of the largest jet $\left(D^{*}\right.$ $=2,9$ ), numerical calculation provides a deviation angle value of
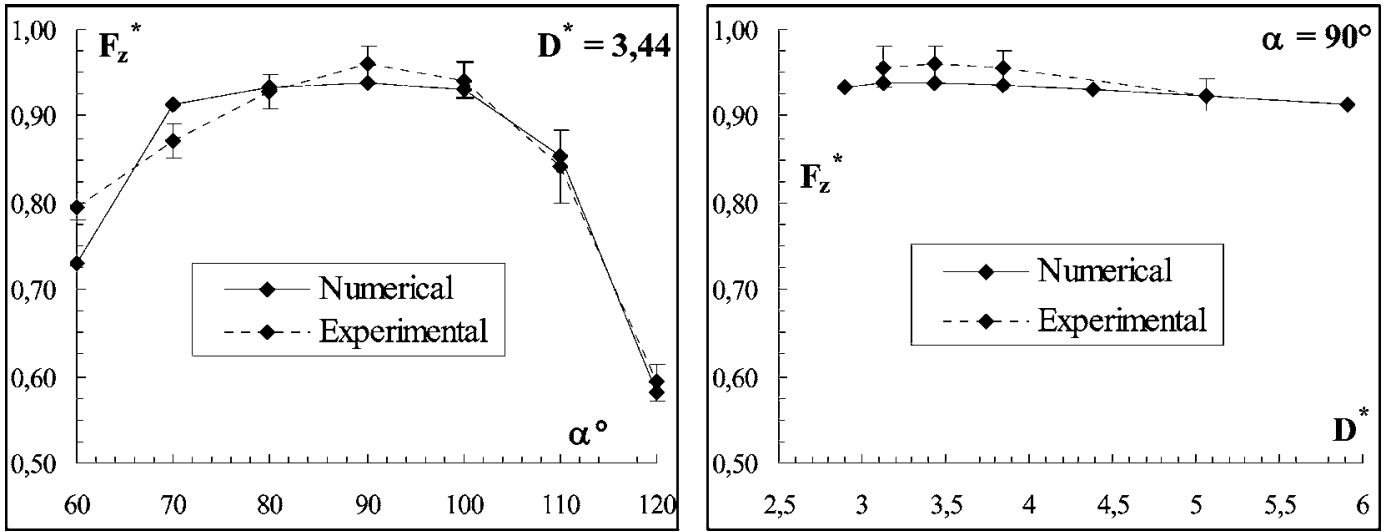

Fig. 17 Total thrust

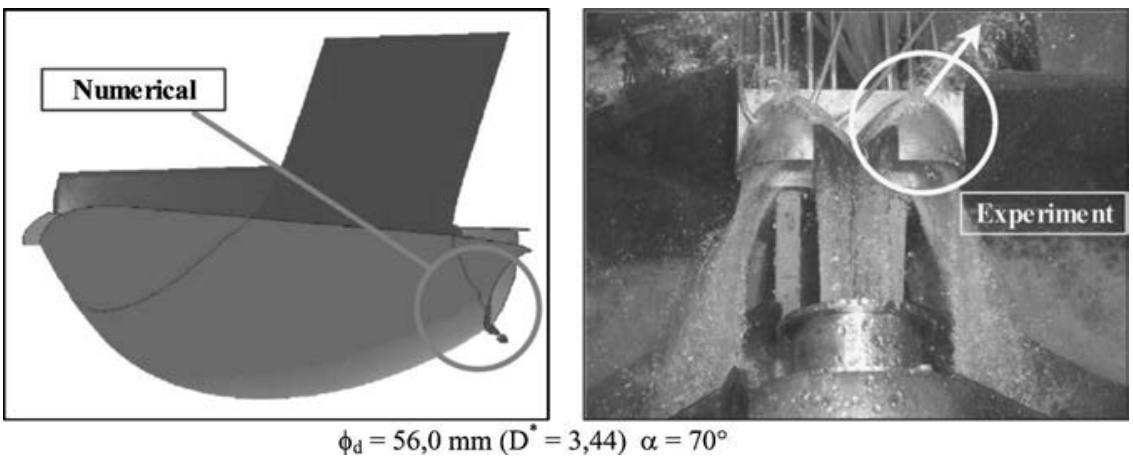

Fig. 18 Cut-out leakage flow rate 


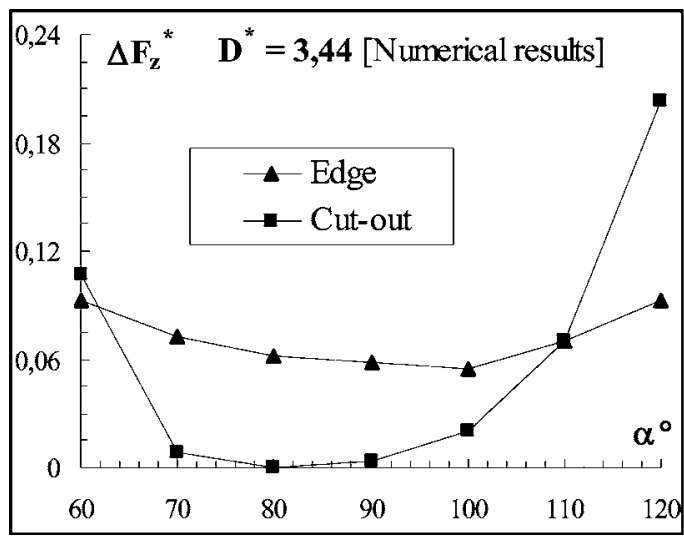

$\sim 2$ deg everywhere on the edge except for the bucket ends. Using the relation (5) in the $2 \mathrm{D}$ configuration case, this deviation angle gives an increase of 0.01 on the edge loss [ $\left.{ }^{*}\right]_{\text {Edge }}$.

Figure 20 represents the graph of four nondimensional magnitudes ${ }^{*}$ num, ${ }^{*}$ exp, ${ }^{*}$, , versus *. The first two correspond to the previous forces obtained, respectively, by the calculation and the experiment. The magnitude indicates the Pelton turbine efficiency.

The nondimensional force ${ }^{*}=1-\quad / \max _{\text {ax }}$ is obtained by keeping only the contribution of the viscous effects to the total loss. Assuming that the boundary layer is little disturbed by the * variation and that the wetted surface variation remains weak, is constant and not varying with * Keeping max proportional to ${ }^{2}$ (relation (3)), one obtains a relative viscous loss proportional to ${ }^{* 2}$ and thus ${ }^{*}=1-\quad{ }^{* 2}$. On the assumption that, at point ${ }_{0}\left({ }^{*}=5.07\right)$, the losses are only of viscous origin, we have ${ }^{*}\left({ }_{0}\right)={ }^{*}{ }_{\exp }\left({ }_{0}\right)$. This relation determines the coefficient . It is noteworthy that the second experimental point (corresponding to ${ }^{*}=3.84$ ) isexactly on the curve ${ }^{*}$. This point separates the inertial zone from the viscous zone. With regard to the inertial zone, the experimental force ${ }^{*}$ exp decreases more quickly than ${ }^{*}$, indicating that the inertial losses become nonnegligible. They consist of losses due to the cutout leakage flow as well as losses due to the streamlines deviation at the bucket edge exit.

The efficiency curve of the Pelton turbine was translated so that the experimental point ${ }_{0}$ belongs to it. It is similar to the curve of the experimental force ${ }_{\text {exp }}^{*}$, in particular, with a maximum in the same area. This similarity occurs owing to the fact that, in the case of a moving bucket, the maximum of thrust is obtained when the jet is approximately perpendicular to the bucket. Finally, it is

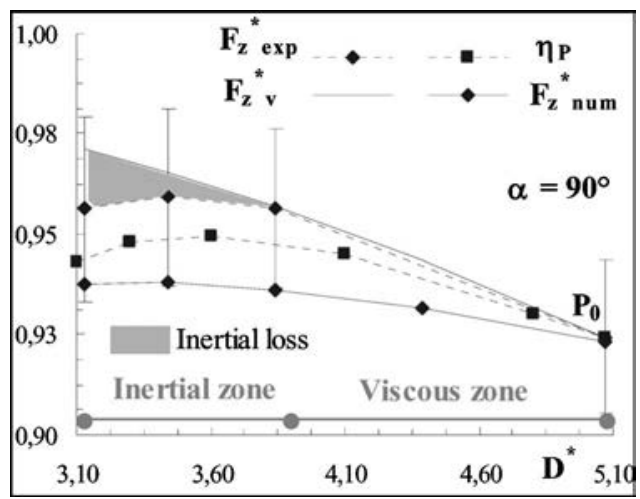

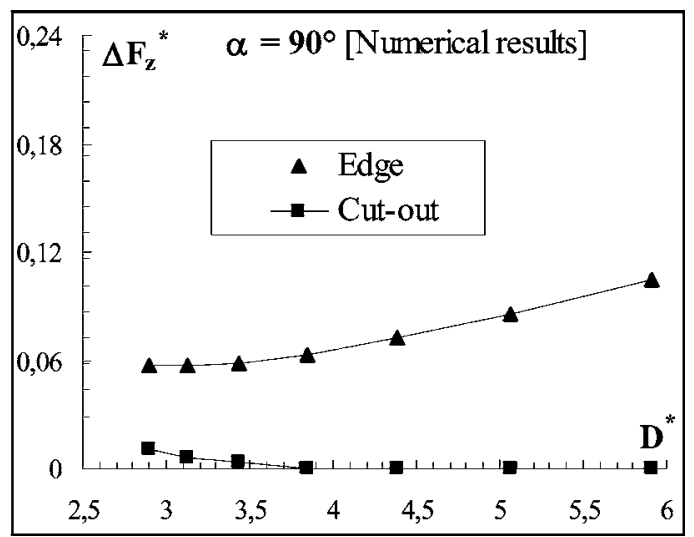

noted that the curve of the calculated force ${ }^{*}$ num presents also a maximum at the same point but with weaker gradients. That comes owing to the fact that the losses estimation is not precise enough. In practice, it is difficult to reduce the viscous losses. In fact, the maximum of thrust is limited by the curve * .

Consequently, if one wants to reduce the losses by a change of design of the fixed bucket, the zone of action to be considered can be only in the inertial zone. In the case of the nominal point $\left({ }^{*}=3.44\right)$, the maximum gain of thrust is $\sim 1 \%$. This gain quickly increases in the case of larger jets: for example, it is $\sim 3 \%$ when $*=3.1$.

In consideration of the previous analysis, the results relative to the fixed bucket provide a first approximation of what one could gain on the efficiency of a Pelton turbine.

\section{Conclusion}

The experimental and numerical studies of the flow inside a Pelton turbine bucket under fixed configuration were carried out. Three heads, four jet diameters, and seven bucket incidences were studied in order to cover the range of the operating parameters of a rotating bucket.

The main results of the experimental study are as follows:

- The various tested heads lead to the same pressure distribution on the bucket. Moreover, not any particular influence of the head on the jet trajectory inside the bucket was noted.

- In all the cases of varying incidence and diameter, a leakage flow through the cutout is found. This flow rapidly increases with the jet diameter and the bucket incidence.

- The pressure force origin is located near the reference plane except for high incidences for which it moves toward the cutout.

The numerical modeling quality is demonstrated by the low relative difference between the calculated pressures and the measured pressures. It is confirmed by the results regarding the total of all forces. The only difference relates to the flow rate loss through the cutout. The numerical process underestimates this leakage flow rate. The analysis of the losses of force due to the edge and the cutout reveals the following points:

- The losses due to edge slightly vary with the incidence and decrease with the jet diameter.

- The losses due to cutout are lower than those due to edge except at extreme incidences, at which they become dominating.
5 I F
$\mathbf{S}$
$\mathbf{P}$
M P T T F T
P S E
F S M P F S H F E N F F S T 
eters). In the inertial zone, the analysis shows that one can gain from $1 \%$ to $3 \%$ on the bucket thrust.

The analogy between the Pelton turbine efficiency and the force on the fixed bucket shows that one can carry out part of the optimization of the rotating bucket using analysis performed on the fixed bucket (edge and cutout). The rotating bucket optimization requires further study relating to the following phenomena: unsteady feeding, centrifugal and Coriolis forces, back splashing, and interference of the sheets of water.

\section{Nomenclature}

$$
\begin{aligned}
& C_{p}=\text { pressure coefficient } \\
& D=\text { jet diameter }(\mathrm{m}) \\
& D_{p}=\text { Pelton diameter }(\mathrm{m}) \\
& F_{z}=\text { Pelton driving force }(\mathrm{N}) \\
& F_{z \max }=\text { Pelton driving force for an ideal bucket }(\mathrm{N}) \\
& g=\text { Gravitational acceleration }\left(\mathrm{m} / \mathrm{s}^{2}\right) \\
& H_{d}=\text { dynamical head }(\mathrm{m}) \\
& H_{n}=\text { net head }(\mathrm{m}) \\
& H_{s}=\text { static head }(\mathrm{m}) \\
& L_{a}=\text { bucket width }(\mathrm{m}) \\
& L_{S 1}=\text { distance between the measurement axis of } \\
& M \text { and the reference plane (m) } \\
& L_{1}=\text { distance between the measurement axis of } \\
& M \text { and the Pelton wheel axis (m) } \\
& M_{w}=\text { moment of force } F_{z} \text { relative to the Pelton } \\
& \text { wheel axis }(\mathrm{Nm}) \\
& M=\text { moment of force } F_{z} \text { relative to the measure- } \\
& \text { ment axis }(\mathrm{Nm}) \\
& M_{w \max }=\text { moment } M_{w} \text { for an ideal bucket (Nm) } \\
& p=\text { pressure }(\mathrm{Pa}) \\
& p_{\text {atm }}=\text { atmospheric pressure }(\mathrm{Pa}) \\
& Q=\text { jet cross section flow rate }\left(\mathrm{m}^{3} / \mathrm{s}\right) \\
& S=\text { cross section of the narrowed jet }\left(\mathrm{m}^{2}\right) \\
& U=\text { jet velocity }(\mathrm{m} / \mathrm{s}) \\
& O x=x \text {-axis perpendicular to the plane of symme- } \\
& \text { try }(\mathrm{m}) \\
& O y=y \text {-axis perpendicular to the reference plane }
\end{aligned}
$$

$x^{*}=x / L_{a}=$ nondimensional abscissa

$y^{*}=y / L_{a}=$ nondimensional ordinate

$z^{*}=z / L_{a}=$ nondimensional $z$ value

$s^{*}=$ nondimensional curvilinear abscissa

$Y^{+}=\rho y_{p} u_{\tau} / \mu=$ dimensionless near-wall distance

$\operatorname{Re}=\rho U D / \mu=$ Reynolds number

$\mathrm{Fr}=U / \sqrt{g L_{a}}=$ Froude number

\section{References}

[1] Parkison, E., Garcin, H., Bissel, C., Muggli, F., and Braune, A., 2002, "Description of Pelton Flow Patterns With Computational Flow Simulations," Symposium Hydropower, Turkey, Nov 4-7, 2002.

[2] Nakanishi, Y., Kubota, T., and Shin, T., 2002, "Numerical Simulation of Flows on Pelton Buckets by Particle Method: Flow on a Stationary/Rotating Flat Plate," Proceedings of 21th IAHR Symposium, Lausanne, Sept. 9-12.

[3] Agarwal, A. K., Harwani, L. K., and Ramanthan, S. M., 2004, "Custom Design of Pelton Turbine Runners by Numerical Analysis," Proceedings of 22th IAHR Symposium, Stockholm, June 29-July 2.

[4] Kubota, T., Jinjong, X., Masuda, J., and Nakanishi, Y, 1998, "Numerical Analysis of Free Water Sheet Flow of Pelton Buckets," Proceedings of 19th IAHR Symposium, Singapore, pp. 316-329.

[5] Liu, J., Han, F., Kubota, T., and Masuda, J., 2002, "Effect of Free Jet Enlargement on the Bucket Flow in Pelton Turbine," Proceedings of 21th IAHR Symposium, Lausanne, Sept. 9-12.

[6] Hana, M., 1999, "Numerical Analysis of Non-Stationary Free Surface Flow in a Pelton Bucket," Ph.D. thesis, Norwegian University of Science and Technology.

[7] Janetzky, B., Göde, E., Ruprecht, A., Keck, H., and Schärer, C., 1998, "Numerical Simulation of the Flow in a Pelton Bucket," Proceedings of 19th IAHR Symposium, Singapore, pp. 276-283.

[8] Avellan, F., Dupont, Ph., Kvicinsky, S, Chapuis, L., Parkinson, E., and Vullioud, G., 1998, "Flow Calculations in Pelton turbines-Part 2: Free Surface Flows," Proceedings of 19th IAHR Symposium, Singapore, pp. 294-305.

[9] Kvicinsky, S., Kueny, J. L., and Avellan, F., 2002, "Numerical and Experimental Analysis of Free Surface Flow in a 3D Nonrotating Pelton Bucket," Proceedings of 9th International Symposium on Transport Phenomena and Dynamics of Rotating Machinery, Honolulu, Feb. 10-14.

[10] Traversaz, M., Leroy, P., Zoppé, B., and Maitre, T., 2002, "Numerical Study of Pelton Bucket Flow: Comparison of FluENT and CFX Results," Proceedings of 21th IAHR Symposium, Lausanne, Sept. 9-12.

[11] Kvicinsky, S., 2002, "Méthode d'Analyse des Écoulements 3D à Surface Libre: Application aux Turbines Pelton," Thèse No. 2526, Ecole Polytechnique Fédérale de Lausanne.

[12] Mack, R., and Moser, W., 2002, "Numerical Investigation of the Flow in a Pelton Turbine," Proceedings of 21th IAHR Symposium, Lausanne, Sept 9-12.

[13] Mack, R., Aschenbrenner, T., Rohne, W., and Farhat, M., 2004, "Validation of Bucket Flow Simulation Using Dynamic Pressure Measurements," Proceedings of 22th IAHR Symposium, Stockholm, June 29-July 2.

[14] Zoppé, B., 2004, "Simulation Numérique et Analyse de l'Écoulement dans les Augets des Turbines Pelton," Thèse, Institut National Polytechnique de Grenoble, France.

[15] Kubota, T., 1989, "Observation of Jet Interference in 6-Nozzle Pelton Turbine," J. Hydraul. Res., 27(6), pp. 753-767.

[16] Perrig, A., Farhat, M., Avellan, F., Parkison, E., Garcin, H., Bissel, C., Valle, M., and Favre, J., 2004, "Numerical Flow Analysis in a Pelton Turbine Bucket," Proceedings of 22th IAHR Symposium, Stockholm, June 29-July 2.

[17] Ishii, M., 1975, Thermo Fluid Dynamic-Theory of Two-Phase Flow, Collection Direction Etudes Recherches Electrécité de France, Eyrolles.

[18] Hirt, C. W., and Nichols, B. D., 1981, "Volume of Fluid Method for the Dynamics of Free Boundaries," J. Comput. Phys., 39(1), pp. 201-225.

[19] Youngs, D. L., 1982, "Time Dependent Multi-Material Flow With Large Fluid Distorsion," Numerical Methods for Fluid Dynamics, Academic Press, New York.

[20] Cousteix, J., 1986, "Three-Dimensional and Unsteady Boundary Layer Computation," Annu. Rev. Fluid Mech., 18, pp. 173-196. 